CHRONIC OBSTRUCTIVE PULMONARY DISEASE

\title{
Inhaled corticosteroids reduce the progression of airflow limitation in chronic obstructive pulmonary disease: a meta- analysis
}

\author{
E R Sutherland, H Allmers, N T Ayas, A J Venn, R J Martin
}

Thorax 2003;58:937-941

See end of article for authors' affiliations

Correspondence to: DrE R Sutherland, 1400 Jackson Street, J-217

Denver, Colorado 80206, USA; sutherlande@njc.org

Received 11 April 2003 Accepted for publication 29 July 2003

Background: Chronic obstructive pulmonary disease (COPD) is a syndrome of chronic progressive airflow limitation which occurs as a result of chronic inflammation of the airways and lung parenchyma. However, the role of inhaled corticosteroids in the treatment of COPD is controversial. We hypothesised that inhaled corticosteroids reduce the progression of airflow limitation in COPD.

Methods: A comprehensive literature search was conducted and data were analysed using random effects methodology. The effect of inhaled steroids on annual change in forced expiratory volume in 1 second $\left(\mathrm{FEV}_{1}\right)$ was determined for all trials, for trials with high dose treatment regimens, and for trials in subjects with moderate to severe airflow limitation.

Results: Data from eight controlled clinical trials of $\geqslant 2$ years were included ( $n=3715$ subjects). Metaanalysis of all study data revealed that inhaled corticosteroids reduce the rate of $\mathrm{FEV}_{1}$ decline by $7.7 \mathrm{ml} /$ year $(95 \%$ confidence interval $(\mathrm{Cl}) 1.3$ to $14.2, \mathrm{p}=0.02)$. Meta-analysis of studies with high dose regimens revealed a greater effect of $9.9 \mathrm{ml} /$ year $(95 \% \mathrm{Cl} 2.3$ to $17.5, \mathrm{p}=0.01)$ compared with the meta-analysis of all studies.

Conclusions: Inhaled corticosteroid treatment for $\geqslant 2$ years slows the rate of lung function decline in COPD. The effect observed with high dose regimens is greater than that with all regimens combined. These data suggest a potential role for inhaled corticosteroids in modifying the long term natural history of COPD.

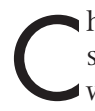
hronic obstructive pulmonary disease (COPD) is a syndrome of chronic and progressive airflow limitation which occurs as a result of chronic inflammation of the airways and lung parenchyma. ${ }^{1}$ Chronic inflammation leads to a progressive deterioration of airflow which is manifested by an accelerated annual rate of decline in the forced expiratory volume in 1 second $\left(\mathrm{FEV}_{1}\right)$ of approximately $60 \mathrm{ml} /$ year. $^{2}$ In comparison, non-smokers experience a rate of decline in $\mathrm{FEV}_{1}$ of approximately $30 \mathrm{ml} / \mathrm{year}^{2}$ This physiological deterioration provides the substrate for the clinical manifestations of COPD, which include cough, sputum production and dyspnoea. Therapeutic options to modify disease progression in COPD are limited and, although pharmacological interventions such as inhaled bronchodilators effectively treat symptoms, they have not been shown to modify the long term progression of airflow limitation.

Inhaled corticosteroids reduce airway inflammation, airflow limitation, and symptoms in asthma and are the mainstay of treatment for patients with persistent asthma. ${ }^{3}$ In COPD, however, the role of inhaled corticosteroids is controversial, as the inflammatory phenotype differs from that seen in asthma ${ }^{1}$ and has been reported to respond less favourably in the short term to inhaled corticosteroids. ${ }^{4}$ There is also ongoing debate surrounding the importance of the physiological versus the clinical response to inhaled corticosteroids. Individual controlled clinical trials comparing inhaled corticosteroids with placebo for treatment periods of 12 months or more have failed to show a significant effect on the rate of decline in $\mathrm{FEV}_{1}$. However, these same trials have shown that medium to high dose $\mathrm{e}^{3}$ inhaled corticosteroids have beneficial effects on clinical outcomes such as symptoms, ${ }^{5}$ exacerbation rate, and health status. ${ }^{67}$ The fact that these drugs have a significant clinical effect even though their physiological effects are negligible may explain why inhaled corticosteroids are prescribed frequently for the treatment of COPD. ${ }^{8}$

We hypothesised that inhaled corticosteroids reduce the progression of airflow limitation in COPD, but that the ability of previous trials to detect a numerically small long term effect on $\mathrm{FEV}_{1}$ has been limited by design considerations including sample size and duration of follow up. To minimise the effect of the early increase in $\mathrm{FEV}_{1}$ seen in many trials of inhaled steroids in COPD, this meta-analysis focused on trials with a duration of $\geqslant 2$ years. The primary outcome measure for this meta-analysis was progression of airflow limitation as reflected by annual decline in $\mathrm{FEV}_{1}$.

\section{METHODS}

Data sources and study selection

A comprehensive search of the published literature was conducted using the medical subject headings chronic obstructive pulmonary disease, chronic bronchitis, pulmonary emphysema, steroids, beclomethasone, budesonide, and triamcinolone and the supplementary terms flunisolide and fluticasone. The search was restricted to clinical trials and MEDLINE (1966-February 2003 (week 2)), CINAHL (1982February 2003 (week 2)), International Pharmaceutical Abstracts (1970-February 2003 (week 2)), and the Cochrane controlled trials register (fourth quarter, 2002) were queried. Reference lists from retrieved articles were reviewed to identify additional candidates for inclusion. Attempts were made to identify additional data or unpublished studies of inhaled corticosteroids in COPD through discussions with experts in the area of COPD pharmacotherapy at the 2002 American Thoracic Society international meeting.

Included studies met the following criteria: (1) design: randomised controlled clinical trial of an inhaled corticosteroid in subjects with COPD; (2) follow up: minimum of 1 year; 
(3) primary outcome variable: change in $\mathrm{FEV}_{1}$ over time; (4) disease-specific factors: subjects with asthma were excluded and subjects were studied when the disease was stable; and (5) publication type: not published solely in abstract form.

The results of the literature search were then sorted, using the criteria above, for inclusion in the meta-analysis (fig 1 ). Pertinence of these citations to the meta-analysis was evaluated using a sequential screening approach beginning with the title, followed by evaluation of the abstract and then the paper itself. Screening of citations was performed individually by each author and trials were selected and agreed upon by consensus.

\section{Outcome variable}

The primary outcome for this meta-analysis was annual rate of change in $\mathrm{FEV}_{1}$, a primary end point for which multiple individual trials of inhaled corticosteroid therapy have been unable to show a significant effect.

\section{Data extraction and quality}

Data regarding the primary outcome variable were abstracted from each article and confirmed by consensus. With one exception, ${ }^{9}$ investigators modelled the mean annual change in $\mathrm{FEV}_{1}$ to take into account the correlated nature of repeated measures within individuals. One of the eight trials ${ }^{10}$ reported a median change in $\mathrm{FEV}_{1}$ over time. After an unsuccessful attempt to obtain mean values for the primary outcome from this large study $(\mathrm{n}=1277)$, an assumption was made that the median value approximated the mean, and standard error was estimated from the reported $\mathrm{p}$ value ${ }^{11}$ for the median

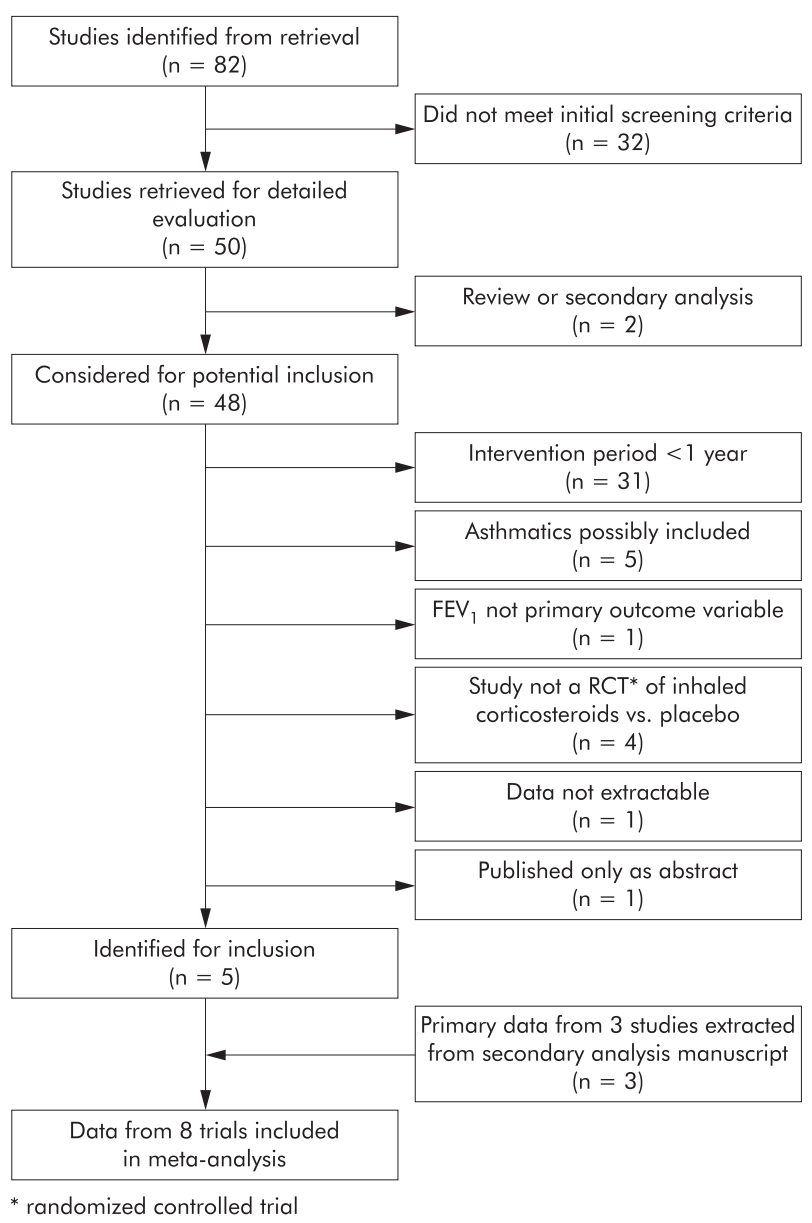

Figure 1 Flow diagram depicting the selection of studies for metaanalysis. differences. The assumed mean and estimated standard error conformed closely to outcome data reported in other clinical trials. Standard error was calculated from the $95 \%$ confidence interval where necessary. ${ }^{12}$ Data reflecting change over the entire study period were abstracted for use in the metaanalysis.

\section{Statistical analysis}

The random effects model of DerSimonian and Laird ${ }^{13}$ was used to perform quantitative synthesis of the extracted data. Random effects methodology was chosen to account for both within study and between study variation. ${ }^{14}$ Summary effect estimates were represented as a point estimate and $95 \%$ confidence intervals and plotted on a forest plot. ${ }^{15}$ Heterogeneity of data was evaluated using the $Q$ statistic. ${ }^{16}$ Publication bias was evaluated by means of a funnel plot $^{17}$ and formal statistical analysis. ${ }^{18}$ STATA software version 7 (STATA Corporation, College Station, Texas) was used for all analyses.

\section{RESULTS}

\section{Study selection}

The literature search strategy identified 82 unique and potentially relevant citations (fig 1). Review of bibliographies and discussion with experts did not uncover additional studies. Thirty two citations did not meet initial screening criteria, leaving 50 citations for which abstracts were reviewed for inclusion. Of these abstracts, one was a qualitative review of inhaled corticosteroids in COPD and one was a secondary pooled analysis of primary data from three prior clinical trials. Of the remaining 48 abstracts, 43 were excluded for the following reasons: follow up was less than 1 year $(n=31)$, subjects with asthma were possibly included $(n=5), \mathrm{FEV}_{1}$ was not the primary outcome variable $(\mathrm{n}=1)$, study was not a randomised controlled clinical trial of inhaled corticosteroids versus placebo $(n=4)$, data were not extractable $(\mathrm{n}=1)$, or the study was published in abstract form only $(\mathrm{n}=1)$.

The five remaining studies 591012 were included in this meta-analysis. Close evaluation of the secondary analysis paper $^{19}$ revealed it to be an analysis of data from three prior clinical trials of long term inhaled corticosteroids ${ }^{20-22}$ in which, in some cases, a mixed population of subjects with asthma and COPD were evaluated. The authors obtained the original study data for subjects with COPD and performed a pooled analysis of the data from these subjects. ${ }^{19}$ Because of their pertinence to this meta-analysis, these data were included, making data from subjects enrolled in a total of eight individual studies available for meta-analysis.

\section{Subject and study characteristics}

Data for 3715 subjects were available for meta-analysis. Table 1 reports age, baseline $\mathrm{FEV}_{1}$ as percentage predicted, $\mathrm{FEV}_{1}$ percentage reversibility in response to inhaled betaagonist, and smoking prevalence for the placebo and steroid arms of each study. Table 2 reports the number of subjects by treatment allocation, drug used for treatment, and duration of treatment for each study. Although the search strategy was designed to identify studies with a duration of as little as 1 year, all studies were $\geqslant 2$ years in duration. The annual change in the rates of $\mathrm{FEV}_{1}$ decline from each study is reported in table 3 .

\section{Effect of inhaled corticosteroids on FEV}

Random effects meta-analysis of data from all studies indicated that inhaled corticosteroids significantly reduced the rate of decline in $\mathrm{FEV}_{1}$ by $7.7 \mathrm{ml} / \mathrm{year}$ (95\% confidence interval (CI) 1.3 to $14.2, \mathrm{p}=0.02$; fig 2 ). 
Table 1 Age, physiological characteristics, and smoking status of study subjects randomised to receive placebo or inhaled corticosteroid

\begin{tabular}{|c|c|c|c|c|c|c|c|c|}
\hline \multirow[b]{2}{*}{ Study } & \multicolumn{2}{|l|}{ Age } & \multicolumn{2}{|c|}{$\mathrm{FEV}_{1}(\%$ predicted $)$} & \multicolumn{2}{|c|}{ \% Reversibility } & \multicolumn{2}{|c|}{ \% Smokers } \\
\hline & Placebo & Steroid & Placebo & Steroid & Placebo & Steroid & Placebo & Steroid \\
\hline Burge ef $a l^{7}$ & $63.8(7.1)$ & $63.7(7.1)$ & $50.0(14.9)$ & $50.3(14.9)$ & $4.4(3.4)$ & $4.4(3.5)$ & 39.2 & 36.4 \\
\hline $\begin{array}{l}\text { Lung Health Study Research } \\
\text { Group }\end{array}$ & $56.4(6.8)$ & $56.2(6.8)$ & $67.2(12.7)$ & 68.5 (12.8) & $6.8(7.7)$ & $6.5(7.3)$ & 89.8 & 90.5 \\
\hline Pauwels et al ${ }^{10}$ & $52.4(7.7)$ & $52.5(7.5)$ & $76.9(13.2)$ & $76.8(12.4)$ & $2.8(3.6)$ & $2.9(3.8)$ & 100 & 100 \\
\hline van Grunsven et al ${ }^{19}$ & $61(7)$ & $61(7)$ & $44.0(10.0)$ & $46.0(11.0)$ & $2.9(2.5)$ & $3.2(2.7)$ & 39 & 34 \\
\hline Vestbo et $a l^{12}$ & $59.1(9.7)$ & $59.0(8.3)$ & $86.9(21.1)$ & $86.2(20.6)$ & $7.2(9.4)$ & $8.1(8.9)$ & 77.2 & 75.9 \\
\hline Weir et $a l^{9 *}$ & $67.6(1.0)$ & $65.5(1.0)$ & $41.4(16.0)$ & $39.7(14.0)$ & $11.5 \dagger$ & $11.2 \dagger$ & 42.9 & 34.7 \\
\hline
\end{tabular}

Data reported as mean (SD) except *mean (SE).

†Calculated from data reported in paper, absolute change $130 \mathrm{ml}$ in placebo group and $120 \mathrm{ml}$ in steroid group.

Sensitivity analyses were performed to determine whether there was an increased response to high dose $^{3}$ inhaled corticosteroids and whether inhaled steroids had a greater effect in subjects with baseline $\mathrm{FEV}_{1} \leqslant 50 \%$ of predicted. Meta-analysis of trials with high dose steroid regimens $(\mathrm{n}=2416)^{7} 9^{10}{ }^{12}$ demonstrated a greater reduction in the rate of $\mathrm{FEV}_{1}$ decline of $9.9 \mathrm{ml} /$ year (95\% CI 2.3 to $17.5, \mathrm{p}=0.01$ ) than was seen in the meta-analysis of all studies (fig 3). Comparison meta-analysis of studies with lower dose regimens could not be performed as only one of the included studies (the Lung Health Study ${ }^{5}$ ) used a non high-dose regimen. The secondary analysis of van Grunsven and colleagues $^{19}$ pooled data from subjects who were treated with a mixture of medium and high dose regimens and these data were therefore not appropriate for inclusion in the analysis of lower dose studies.

In studies which enrolled subjects with a baseline $\mathrm{FEV}_{1}$ of $\leqslant 50 \%$ predicted $(\mathrm{n}=1032$ subjects $),{ }^{79}{ }^{19}$ a reduction in the rate of decline in $\mathrm{FEV}_{1}$ of $18.3 \mathrm{ml} /$ year was observed, but the $95 \%$ confidence interval was not significant ( -1.5 to $38.0 \mathrm{ml} /$ year, $\mathrm{p}=0.07)$.

\section{Statistical heterogeneity and publication bias}

For the analysis of all studies there was no evidence of significant statistical heterogeneity $(Q=5.9, \quad \mathrm{p}=0.32)$. Furthermore, there was no evidence of significant statistical heterogeneity in the analysis of studies which used high dose inhaled corticosteroid regimens $(Q=2.4, \mathrm{p}=0.50)$ or in the analysis of studies which enrolled subjects with a baseline $\mathrm{FEV}_{1}$ of $\leqslant 50 \%$ predicted $(Q=2.8, \mathrm{p}=0.25)$.

Funnel plot analysis (fig 4$)^{17}$ of the included studies demonstrated asymmetry with an $\operatorname{Egger}^{18} \mathrm{p}=0.03$, suggesting that there was publication bias manifested by an absence in the literature of studies that resulted in negative mean effect estimates with high standard errors.

\section{DISCUSSION}

The results of this meta-analysis suggest that inhaled corticosteroids significantly slow the rate of deterioration in $\mathrm{FEV}_{1}$ in patients with COPD when used for a period of at least 24 months. This effect appears to be augmented by high dose regimens $s^{3}$ of inhaled corticosteroids.

The size of the effect derived from inhaled corticosteroids is numerically small, with the reduction in the rate of $\mathrm{FEV}_{1}$ decline ranging from 7.7 to $9.9 \mathrm{ml} /$ year. Although these numbers are small in the absolute, they represent a relative reduction in the rate of $\mathrm{FEV}_{1}$ decline of approximately 13$17 \%$ in smokers with COPD and $26-33 \%$ in non-smokers with COPD. ${ }^{2}$ This effect of inhaled corticosteroids on the rate of $\mathrm{FEV}_{1}$ decline is less than the effect of smoking cessation, which can achieve a reduction of approximately $50 \%$ in the rate of deterioration. ${ }^{2}$ However, many of the subjects contributing data to this meta-analysis continued to smoke during inhaled corticosteroid treatment, suggesting that the beneficial effect of inhaled corticosteroids occurs despite an ongoing inflammatory stimulus.

Current guidelines recommend that inhaled corticosteroids be administered to COPD patients with frequent symptoms despite optimal bronchodilator therapy, frequent exacerbations, and $\mathrm{FEV}_{1}$ of $\leqslant 50 \%$ predicted. ${ }^{23}$ Analysis of studies on this population showed a trend towards a greater effect that did not achieve statistical significance. Further research is required to determine which patients respond best to inhaled corticosteroids and whether this effect is greater in patients with low $\mathrm{FEV}_{1}$. Although we were able to show a larger effect size with studies of high dose regimens compared with all studies, only one lower dose study ${ }^{5}$ was available for comparison, preventing a comparison meta-analysis and possibly limiting the ability to draw conclusions about dose-response. The majority of long term studies of inhaled corticosteroids in COPD have used high dose regimens and, although the greater effect size seen in high dose studies may

Table 2 Number of subjects and treatment allocation by study

\begin{tabular}{|c|c|c|c|c|}
\hline \multirow[b]{2}{*}{ Study } & \multicolumn{2}{|l|}{$\mathrm{N}$} & \multirow[b]{2}{*}{ Drug } & \multirow{2}{*}{$\begin{array}{l}\text { Duration of } \\
\text { treatment }\end{array}$} \\
\hline & Placebo & Steroid & & \\
\hline Burge et $a l^{7}$ & 375 & 376 & Fluticasone, $500 \mu \mathrm{g}$ bid & 36 months \\
\hline $\begin{array}{l}\text { Lung Health Study } \\
\text { Research Group }\end{array}$ & 557 & 559 & Triamcinolone, $600 \mu \mathrm{g}$ bid & 40 months \\
\hline Pauwels et al ${ }^{10}$ & 643 & 634 & Budesonide, $400 \mu \mathrm{g}$ bid & 36 months \\
\hline van Grunsven et al ${ }^{19}$ & 88 & 95 & $\begin{array}{l}\text { Beclomethasone, } 800 \mu \mathrm{g} \text { or } 1500 \mu \mathrm{g} \mathrm{qd} \text {, } \\
\text { or budesonide, } 800 \mu \mathrm{g} \text { bid }\end{array}$ & $24-30$ months \\
\hline Vestbo et $a l^{12}$ & 145 & 145 & $\begin{array}{l}\text { Budesonide, } 800 \mu \mathrm{g} \mathrm{qam} / 400 \mu \mathrm{g} \mathrm{qpm} \times \\
6 \text { months, then } 400 \mu \mathrm{g} \text { bid }\end{array}$ & 36 months \\
\hline Weir et al ${ }^{9}$ & 49 & 49 & $\begin{array}{l}\text { Beclomethasone, } 750 \mu \mathrm{g} \text { (if weight }<50 \mathrm{~kg} \text { ) } \\
\text { or } 1000 \mu \mathrm{g} \text { bid (if weight } \geqslant 50 \mathrm{~kg} \text { ) }\end{array}$ & 24 months \\
\hline
\end{tabular}


Table 3 Annual rate of decline in post-bronchodilator $\mathrm{FEV}_{1}$ by treatment allocation

\begin{tabular}{|c|c|c|c|}
\hline \multirow[b]{2}{*}{ Study } & \multicolumn{2}{|c|}{ Annual change in $\mathrm{FEV}_{1}(\mathrm{ml} /$ year) } & \multirow{2}{*}{$\begin{array}{l}\text { Reduction in annual change } \\
\text { in } \mathrm{FEV}_{1}(\mathrm{ml} / \text { year) }\end{array}$} \\
\hline & Placebo & Steroid & \\
\hline $\begin{array}{l}\text { Burge et al } \\
\text { Lung Health Study } \\
\text { Research Group }\end{array}$ & $\begin{array}{l}-59(4.4) \\
-47.0(3.0)\end{array}$ & $\begin{array}{l}-50(4.1) \\
-44.2(2.9)\end{array}$ & $\begin{array}{l}9.0(6.0) \\
2.8(4.2)\end{array}$ \\
\hline $\begin{array}{l}\text { Pauwels et } a l^{10} \\
\text { van Grunsven et al }{ }^{19} \\
\text { Vestbo et } a l^{12} \\
\text { Weir et } a l^{9}\end{array}$ & $\begin{array}{l}-60 \dagger \\
N R \\
-49.1^{*} \\
-56.9(15)\end{array}$ & $\begin{array}{l}-46.7 \dagger \\
N R \\
-46.0^{*} \\
-20.6(16)\end{array}$ & $\begin{array}{l}13.3(6.8) \dagger \\
39.0(23.0) \\
3.1(8.1) \\
36.3(22.3)\end{array}$ \\
\hline
\end{tabular}

be evidence of a dose-response effect, it may also reflect issues related to sample size and statistical heterogeneity.

The clinical importance of an improvement in $\mathrm{FEV}_{1}$ of 7.7$9.9 \mathrm{ml} /$ year is debatable. However, as noted previously, many of the trials included in this meta-analysis showed a benefit of inhaled corticosteroids with regard to secondary outcome measures such as exacerbation frequency, symptom scores, and quality of life. Exacerbations contribute to the decline in lung function in COPD, ${ }^{24}$ and the effect of inhaled steroids on $\mathrm{FEV}_{1}$ may be mediated in part by a reduction in exacerbation frequency. Additionally, the physiological benefit of inhaled corticosteroids may not be reflected by changes in $\mathrm{FEV}_{1}$ but rather by changes in lung volumes and hyperinflation, as occurs with inhaled bronchodilators. ${ }^{25}$ Although the numerical effect of inhaled steroids is small, these drugs do have a moderate relative effect and may supplement other interventions such as smoking cessation in modifying the natural history of this disease. The fact that studies with a follow up of $\geqslant 2$ years were included in this meta-analysis may underestimate the beneficial short term effects of inhaled steroids. In many clinical trials of these drugs in COPD there is an increase in $\mathrm{FEV}_{1}$ over the initial months of treatment, so we chose long term studies to avoid an undue influence of this early increase on the long term outcome. However, we did not have access to the primary data necessary formally to test the effect of this initial increase on the overall outcome, and further studies are needed to determine the effect of this initial increase on the overall response.

The choice of primary end points also affects interpretation of clinical trials of inhaled corticosteroids in COPD, and improving $\mathrm{FEV}_{1}$ has been an elusive goal in clinical trials in patients with this condition. $\mathrm{FEV}_{1}$ is poorly correlated with symptom indices, ${ }^{23}$ and improvement in $\mathrm{FEV}_{1}$ may be a

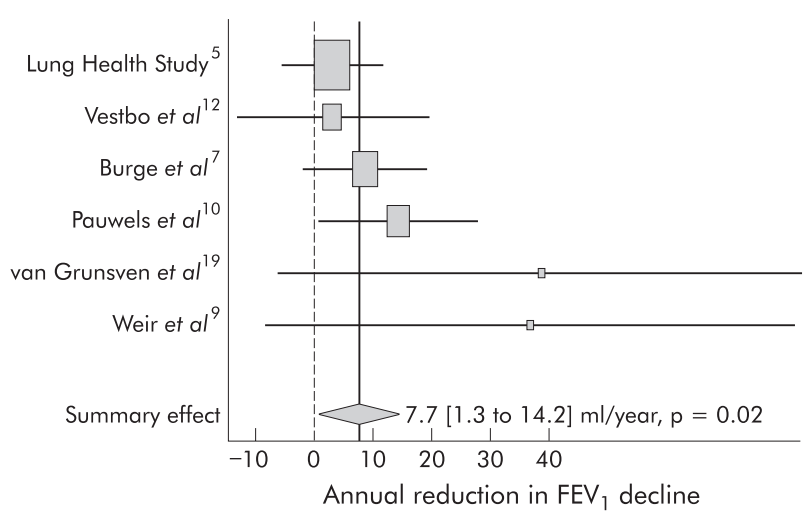

Figure 2 Summary effect of inhaled corticosteroids on the rate of decline in post-bronchodilator $F E V_{1}$ in patients with COPD. The centre of the diamond indicates the summary effect and its width the $95 \%$ confidence interval. suboptimal choice of primary outcome for clinical trials. Many of the trials included in this meta-analysis reported significant results for secondary end points including symptom scores, quality of life and exacerbation rates, an effect confirmed in a recent meta-analysis of exacerbation rates in short and long term trials of inhaled corticosteroids in COPD. ${ }^{26}$ It should be noted that, in seven of the eight included studies, a modelled rather than crude estimate of post-bronchodilator $\mathrm{FEV}_{1}$ change was reported. Although this may have improved our ability to detect a positive effect, modelling is a necessary and appropriate means of accounting for the correlated nature of longitudinal spirometric data.

This meta-analysis has limitations. Although we did not find any evidence of statistical heterogeneity, there is design heterogeneity between the included studies with regard to factors such as pre-randomisation physiology, smoking prevalence, drug dosing, and study duration. This is likely to have an impact on inhaled corticosteroid efficacy, but it may also more fairly represent the real life clinical variation seen in the treatment of patients with COPD. However, our inclusion of only randomised studies forced these factors to be distributed randomly in the study population, reducing the likelihood that they were significant confounders. There is a suggestion of publication bias in that there is an absence of small studies with negative outcomes in the reported literature. Whether this represents true publication bias or whether studies with such results have been performed is unclear. There is no shortage of large studies with negative outcomes, and it is unlikely that identifying small negative studies would significantly impact on these results. Finally, as is often the case in meta-analyses of published literature, data quality differed between studies. For example, only $72 \%$ of included data were specified by original investigators to have been analysed by intent-to-treat principles, and median (rather than mean) outcome data were used in one case.

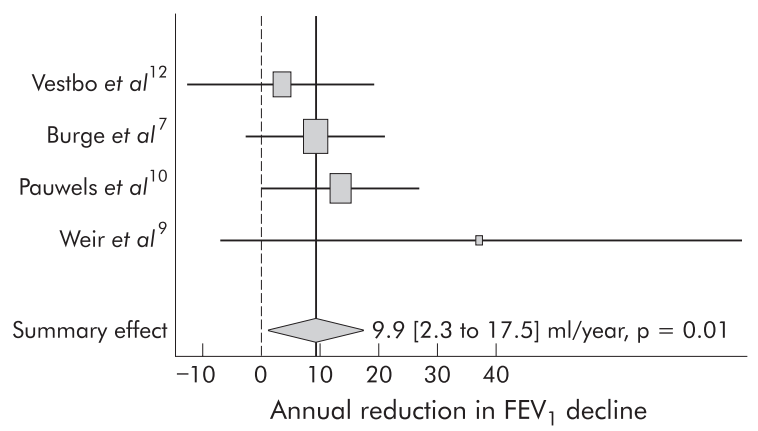

Figure 3 Summary effect of high dose inhaled corticosteroids on the rate of decline in post-bronchodilator $\mathrm{FEV}_{1}$ in patients with COPD. The centre of the diamond indicates the summary effect and its width the $95 \%$ confidence interval. 


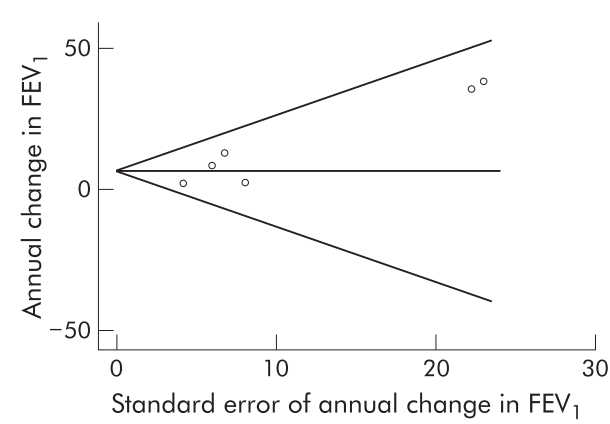

Figure 4 Funnel plot of included studies.

In summary, these data suggest that inhaled corticosteroids significantly slow the rate of decline in $\mathrm{FEV}_{1}$ in patients with COPD. The effect is numerically small but represents a moderate relative effect compared with interventions such as smoking cessation. Further clinical data from studies of inhaled corticosteroids are necessary to inform clinicians more fully as to the appropriate place of these drugs in COPD pharmacotherapy.

\section{ACKNOWLEDGEMENTS}

The authors acknowledge the contribution of Michael A Stoto, PhD to this research.

\section{Authors' affiliations}

E R Sutherland, R J Martin, Department of Medicine, National Jewish Medical and Research Center and the University of Colorado Health Sciences Center, Denver, Colorado, USA

H Allmers, Department of Dermatology, Environmental Medicine and Health Sciences, University of Osnabrueck, Osnabrueck, Germany N T Ayas, Respiratory Division, Department of Medicine, Vancouver General Hospital, and the Centre for Clinical Epidemiology and Evaluation, Vancouver, Canada

A J Venn, Division of Epidemiology and Public Health, University of Nottingham, Nottingham, UK

Funding: NIH K23 HL04385 (Dr Sutherland), The Wellcome Trust (Dr Venn).

\section{REFERENCES}

1 Barnes PJ. Chronic obstructive pulmonary disease. N Engl J Med 2000;343:269-80.

2 Anthonisen NR, Connett JE, Murray RP. Smoking and lung function of Lung Health Study participants after 11 years. Am J Respir Crit Care Med 2002; 166:675-9.

3 National Heart, Lung and Blood Institute. Guidelines for the diagnosis and management of asthma. Bethesda, MD: National Heart, Lung and Blood Institute, 1997.

4 Culpitt SV, Maziak W, Loukidis S, et al. Effect of high dose inhaled steroid on cells, cytokines, and proteases in induced sputum in chronic obstructive pulmonary disease. Am J Respir Crit Care Med 1999;160(5 Pt 1):1635-9.
5 The Lung Health Study Research Group. Effect of inhaled triamcinolone on the decline in pulmonary function in chronic obstructive pulmonary disease. N Engl J Med 2000;343:1902-9.

6 Spencer S, Calverley PM, Sherwood Burge P, et al. Health status deterioration in patients with chronic obstructive pulmonary disease. Am J Respir Crit Care Med 2001;163:122-8.

7 Burge PS, Calverley PM, Jones PW, et al. Randomised, double blind, placebo controlled study of fluticasone propionate in patients with moderate to severe chronic obstructive pulmonary disease: the ISOLDE trial. BMJ 2000;320: 1297-303.

8 Jackevicius CA, Chapman KR. Prevalence of inhaled corticosteroid use among patients with chronic obstructive pulmonary disease: a survey. Ann Pharmacother 1997;31:160-4.

9 Weir DC, Bale GA, Bright $P$, et al. A double-blind placebo-controlled study of the effect of inhaled beclomethasone dipropionate for 2 years in patients with nonasthmatic chronic obstructive pulmonary disease. Clin Exp Allergy 1999:29(Suppl 2):125-8.

10 Pauwels RA, Lofdahl CG, Laitinen LA, et al. Long-term treatment with inhaled budesonide in persons with mild chronic obstructive pulmonary disease who continue smoking. European Respiratory Society Study on Chronic Obstructive Pulmonary Disease. N Engl J Med 1999;340:1948-53.

11 Greenland S. Quantitative methods in the review of epidemiologic literature. Epidemiol Rev 1987;9:1-30

12 Vestbo J, Sorensen T, Lange P, et al. Long-term effect of inhaled budesonide in mild and moderate chronic obstructive pulmonary disease: a randomised controlled trial. Lancet 1999;353:1819-23.

13 DerSimonian R, Laird N. Meta-analysis in clinical trials. Control Clin Trials 1986; 7:177-88.

14 Sutton AJ, Abrams KR, Jones DR, et al. Random effects methods for combining study estimates. Methods for meta-analysis in medical research. Chichester: John Wiley \& Sons, 2000:73-86.

15 Light RJ, Singer JD, Willett JB. The visual presentation and interpretation of meta-analysis. In: Cooper H, Hedges LV, eds. The handbook of research synthesis. New York: Russell Sage Foundation, 1994:439-54.

16 Cochran WG. the combination of estimates from different experiments. Biometrics 1954;10:101-29.

17 Begg CB, Mazumdar M. Operating characteristics of a rank correlation test for publication bias. Biometrics 1994;50:1088-101.

18 Egger M, Davey Smith G, Schneider M, et al. Bias in meta-analysis detected by a simple, graphical test. BMJ 1997;315:629-34.

19 van Grunsven PM, van Schayck CP, Derenne JP, et al. Long term effects of inhaled corticosteroids in chronic obstructive pulmonary disease: a metaanalysis. Thorax 1999;54:7-14.

20 Derenne JP. Effects of high-dose inhaled beclomethasone on the rate of decline in $\mathrm{FEV}_{1}$ in patients with chronic obstructive pulmonary disease: results of a 2 year prospective multicentre study. Am J Respir Crit Care Med 1995; 151:A463.

21 Kerstjens HA, Brand PL, Hughes MD, et al. A comparison of bronchodilator therapy with or without inhaled corticosteroid therapy for obstructive airways disease. Dutch Chronic Non-Specific Lung Disease Study Group. N Engl J Med 1992;327:1413-9.

22 Renkema TE, Schouten JP, Koeter GH, et al. Effects of long-term treatment with corticosteroids in COPD. Chest 1996;109:1156-62.

23 Pauwels RA, Buist AS, Calverley PM, et al. Global strategy for the diagnosis, management, and prevention of chronic obstructive pulmonary disease. NHLBI/WHO Global Initiative for Chronic Obstructive Lung Disease (GOLD) workshop summary. Am J Respir Crit Care Med 2001;163:1256-76.

24 Donaldson GC, Seemungal TA, Bhowmik A, et al. Relationship between exacerbation frequency and lung function decline in chronic obstructive pulmonary disease. Thorax 2002;57:847-52.

25 Boni E, Corda L, Franchini D, et al. Volume effect and exertional dyspnoea after bronchodilator in patients with COPD with and without expiratory flow limitation at rest. Thorax 2002;57:528-32.

26 Alsaeedi A, Sin DD, McAlister FA. The effects of inhaled corticosteroids in chronic obstructive pulmonary disease: a systematic review of randomized placebo-controlled trials. Am J Med 2002;113:59-65. 